\title{
Analysis of Side Effects from Cosmetic Procedures with Botulinum Toxin
}

\author{
Seung Min Oh, MD, MMBA ${ }^{1}$ \\ Cheol Woo Lee, $\mathrm{MD}^{2}$ \\ Soo Ik Lee, MD ${ }^{3}$ \\ Bong Cheol Kim, $\mathrm{MD}^{4}$ \\ ${ }^{1}$ ON Clinic, Seoul, Korea \\ ${ }^{2}$ MIZEYE Clinic, Seoul, Korea \\ ${ }^{3}$ FORHAIR Clinic, Daegu, Korea \\ ${ }^{4}$ Lamar Clinic, Isu branch, Seoul, Korea
}

Received March 24, 2020

Revised April 10, 2020

Accepted April 15, 2020

\section{Correspondence}

Bong Cheol Kim

Lamar Clinic, Seoul 07008, Korea

E-mail: tazosboy@hanmail.net

https://orcid.org/0000-0003-1701-2406

(C) Korean Society for Laser, Dermatology and Trichology

(c) This is an open access article distributed under the terms of the Creative Commons Attribution NonCommercial License (http://creativecommons.org/ licenses/by-nc/4.0) which permits unrestricted noncommercial use, distribution, and reproduction in any medium, provided the original work is properly cited.

\section{Background and Objectives}

The use of botulinum toxin in cosmetic procedures is widespread. While the side effects of the procedure and problems with resistance due to excessive use are being discussed, studies of clinical patterns of botulinum toxin use and side effects associated therewith are lacking.

\section{Materials and Methods}

In this study, clinical usage patterns for botulinum toxin were analyzed through a web-based, real-time survey conducted at the Korean Association for Laser Dermatology And Trichology Fall Academic Conference held in December 2018. A questionnaire was administered to assess different types and locations of side effects experienced and the frequencies thereof.

Results

The most common side effects that the clinicians reportedly encountered during botulinum toxin treatment were bruising and Mephisto sign from overcorrection. The most common site of side effects was the upper part of the face.

\section{Conclusion}

This study highlights the need to raise awareness of the importance of education on the anatomy of the upper part of the face, where side effects for cosmetic procedures with botulinum toxin are most common, to reduce the possibility thereof.

Key words

Web survey, Complication, Botulinum toxin, Side effect 


\section{INTRODUCTION}

Treatments with botulinum toxin are some of the most frequently performed cosmetic procedures [1]. In the early 2000s, only three to four botulinum toxins were approved for use in cosmetic procedures worldwide. Nowadays; however, not only four toxins developed in korea have been approved for use in Korea, but also another five to six await approval [2]. With its indications continuing to grow [3], use of botulinum toxin at various sites in an off-label format is becoming increasingly popular, although no detailed research on such usage has been conducted.

Recently, concerns have grown concerning side effects associated with and resistance to botulinum toxin [4]. However, a lack of information on actual clinical usage patterns of botulinum toxin hinders efforts to address these issues: attempts to document the side effects of botulinum toxin are limited as most side effects are not life-threatening and generally resolve over time. Nevertheless, detailed analysis of the side effects of botulinum toxin is highly important to developing training programs on toxin use and strategies for managing side effects as they occur.

Therefore, we designed this study to survey clinicians who are actively performing botulinum toxin treatments at healthcare facilities across Korea. The fact-finding survey was conducted to obtain information from the clinicians on clinical patterns of botulinum toxin use and side effects associated therewith.

\section{MATERIALS AND METHODS}

The survey was conducted at the 30th Fall Academic Conference of the Korean Association for Laser, Dermatology and Trichology (KALDAT) held at the Parnas Tower of Grand InterContinental Seoul Parnas in Samsung-dong, Seoul on December 2, 2018. The survey was conducted in real time via the internet on a mobile basis. A text message linked to the questionnaire's webpage was sent to participants at the conference upon registration in order to prevent fraudulent participation. Individuals could only participate in the survey once, and each text message link was embedded with a unique, encrypted number to prevent multiple attempts at the survey. All obtained data were encrypted and were personally unidentifiable. Upon accessing the survey's webpage and prior to participation, participants were presented with and asked to complete a consent form granting the use of their personal information for analysis.

For immediate feedback in conducting web surveys, the webpage authors implemented the long polling technique of the Ajax library using the JavaScript language jQuery, which is commonly used in chat solutions. In doing so, the administrator of the webpage could check the results of the questionnaire in real time without the need to refresh the page.

The questionnaire consisted of 13 questions designed to obtain information on gender, age, and clinical specialization. All questions were multiple choice, and only one question allowed for multiple responses. Responses were collected only when the "Finish" button was pressed after completing the questionnaire.

\section{Statistical analysis}

Univariate analysis was performed to assess factors related with complication sites. All analysis were conducted in Excel (Microsoft. USA).

\section{RESULTS}

In total, 434 participants completed the survey, for an overall response rate of $31.8 \%$. The sociodemographic characteristics of the participants provided in Table 1 . In regards to specialty, clinicians were divided into the following four groups: cosmetic physician, dermatologist, plastic surgeon, and others. The others group comprised physicians who primarily practice general medicine but also perform cosmetic procedures on occasion.

Table 2 comprises information on the usage of botuli-

Table 1. Basic demographics

\begin{tabular}{|c|c|}
\hline Variables & Mean (SD) or N (\%) \\
\hline \multicolumn{2}{|l|}{ Specialty } \\
\hline Cosmetic physician & $251(57.8)$ \\
\hline Dermatologist & 15 (3.5) \\
\hline Plastic surgeon & $30(6.9)$ \\
\hline Others & $138(31.8)$ \\
\hline \multicolumn{2}{|l|}{ Experience } \\
\hline \multicolumn{2}{|l|}{$<1 \mathrm{yr}$} \\
\hline \multicolumn{2}{|l|}{$1 \mathrm{yr}<<3 \mathrm{yrs}$} \\
\hline \multicolumn{2}{|l|}{3 yrs $<<6$ yrs } \\
\hline \multicolumn{2}{|l|}{6 yrs $<$} \\
\hline \multicolumn{2}{|l|}{ Working form } \\
\hline Clinic - Director & $236(54.4)$ \\
\hline Clinic - Physician & $160(36.9)$ \\
\hline Hospital - Physician & $15(3.5)$ \\
\hline Resident & $5(1.2)$ \\
\hline Public health or military physician & $3(0.7)$ \\
\hline
\end{tabular}

Numbers are presented as means \pm S.D or numbers (\%). 
num toxin in cosmetic procedures performed by the survey participants. Most of the participants performed two to five treatments/day, followed by $10-30$ treatments/day and five to 10 treatments/day, in that order. Medytoxin ${ }^{\circledR}$ was the most frequently answered product to the question of which toxin was most preferred, followed by Botulax ${ }^{\circledR}$, and $\mathrm{Nabota}^{\circledR}$. In response to a question on the advised treatment interval to prevent tolerance, most participants responded 3 months or longer, followed by 1 month or lon-

Table 2. Utilization of botulinum toxin in cosmetic procedures

\begin{tabular}{|c|c|c|}
\hline Item & Response & $\mathrm{N}(\%)$ \\
\hline \multirow[t]{5}{*}{ Number of cases } & $<1$ case / day & 75 (17.3) \\
\hline & $2-5$ cases / day & $113(26.0)$ \\
\hline & 5-10 cases / day & $97(22.4)$ \\
\hline & 10-30 cases / day & $107(24.7)$ \\
\hline & > 30 cases / day & $42(9.7)$ \\
\hline \multirow[t]{6}{*}{ Preferred product } & Medytoxin & $224(51.6)$ \\
\hline & Botulax & $141(32.5)$ \\
\hline & Nabota & $25(5.8)$ \\
\hline & Botox & $18(4.2)$ \\
\hline & Xeomin & $9(2.1)$ \\
\hline & Dysport & $1(0.2)$ \\
\hline \multirow{5}{*}{$\begin{array}{l}\text { Procedure interval }(i) \text { for } \\
\text { prevention of intolerance }\end{array}$} & $i<1$ week & $16(3.7)$ \\
\hline & 1 week $<i<1$ month & $53(12.2)$ \\
\hline & 1 month $<i<3$ months & $74(17.1)$ \\
\hline & 3 months $<i<6$ months & $237(54.6)$ \\
\hline & 6 months $<i$ & $54(12.4)$ \\
\hline \multirow[t]{4}{*}{ Usage limit per procedure } & $\begin{array}{l}<100 \mathrm{IU}(300 \mathrm{IU} \text { in } \\
\text { Dysport) }\end{array}$ & $168(38.7)$ \\
\hline & $\begin{array}{l}100-200 \text { IU } \\
\text { (300-600 IU in Dysport) }\end{array}$ & $139(32.0)$ \\
\hline & $\begin{array}{l}200-350 \text { IU } \\
\text { (600-1050 IU in Dys- } \\
\text { port) }\end{array}$ & 109 (25.1) \\
\hline & $\begin{array}{l}>350 \text { IU (>1050 IU in } \\
\text { Dysport) }\end{array}$ & $18(4.2)$ \\
\hline \multirow{5}{*}{$\begin{array}{l}\text { Most frequent } \\
\text { complication }\end{array}$} & Bruising & $155(35.7)$ \\
\hline & Overcorrection & $113(26.0)$ \\
\hline & Patient dissatisfaction & $88(20.3)$ \\
\hline & Asymmetry & $15(3.5)$ \\
\hline & Weakness & $19(4.4)$ \\
\hline \multirow{4}{*}{$\begin{array}{l}\text { Most common } \\
\text { complication site }\end{array}$} & Upper face & $321(74.0)$ \\
\hline & Mid face & $59(13.6)$ \\
\hline & Lower face & $40(9.2)$ \\
\hline & Body & $14(3.2)$ \\
\hline
\end{tabular}

Numbers are presented as means \pm S.D or numbers (\%). ger, and 6 months or longer. When asked about the limit for a safe treatment dose, most of the participants answered less than 100 units, followed by 100-200 units and 200350 units. The most common side effects were bruising, overcorrection, and patient dissatisfaction with their appearance. When asked about how to deal with bruises, the most common answer was to allow for spontaneous healing; next was to prescribe topical agents for bruising. The upper part of the face was the most common site at which side effects occurred.

\section{DISCUSSION}

This study was conducted as a large-scale survey of clinicians who perform cosmetic procedures with botulinum toxin. In general, the response rate for the questionnaire was quite low [5]; however, more than $30 \%$ of the participants in this conference answered the questionnaire through a real-time, web-based mobile questionnaire. Our results revealed that the most common side effects of botulinum toxin treatment are bruising and overcorrection along the upper part of the face.

The primary use of botulinum toxin is to reduce the appearance of wrinkles around the eyes and forehead. To do so, treatment of the corrugator and procerus muscles is essential, particularly around the glabella. The corrugator muscle plays an important role in creating vertical wrinkles in the glabella [6]. In order to paralyze this muscle, it is necessary to inject botulinum toxin accurately into the corrugator muscle above the medial border of both eyebrows. However, the frontalis muscle is located superficial to the corrugator muscle (Fig. 1), and if extra botulinum toxin is

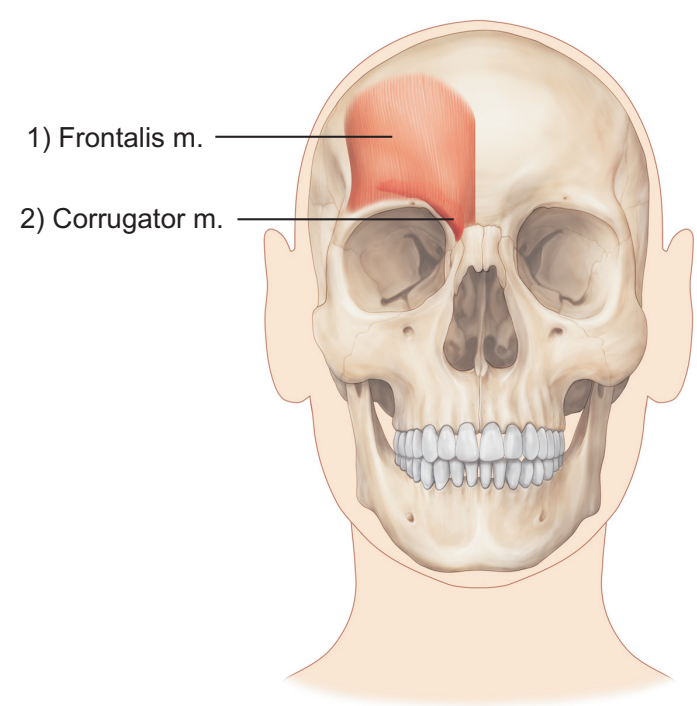

Fig. 1. Frontalis muscle and corrugator muscle. 


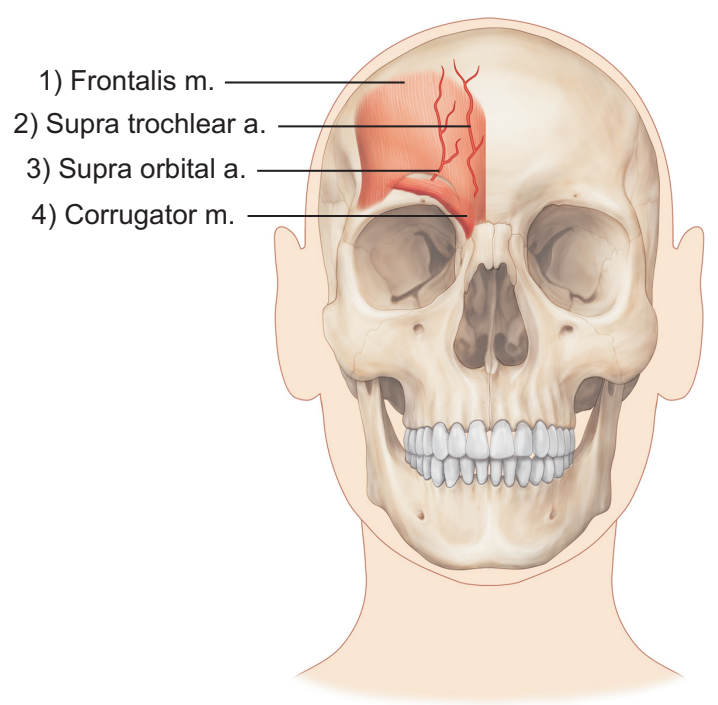

Fig. 2. Supra trochlear artery and supra orbital artery pathway.

injected above the corrugator muscle or if it diffuses to peripheral areas, there is a risk of botulinum toxin spreading to the frontalis muscle causing lifting of the eyebrows upwards and sagging of the glabella. In some instances, only sagging of the glabella occurs, with the outer eyebrows maintaining their normal position, called Mephisto sign [7]. In addition, the supra trochlear and the supra orbital arteries pass through this site, running through the corrugator muscle and the deep layer between the eyebrows (Fig. 2). When botulinum toxin is applied to the corrugator muscle and the supra trochlear artery is damaged, bruising and overcorrection due to spread of the toxin can occur [8].

Botulinum toxin treatment is basically a blind technique. In other words, even if the procedure is performed on a route or depth that is known to be safe, blood vessel damage may occur because the procedure does not allow for direct visualization of all underlying structures. Moreover, blood vessels and the shape and distribution of muscles can differ from individual to individual $[9,10]$. Therefore, even the best efforts based purely on anatomical knowledge of the upper face would be unable to ensure a $100 \%$ safe procedure. Accordingly, we suggest that it may be necessary to apply a precise pre-examination method, potentially ultrasound, that can allow for visualization of blood vessels or muscle distributions to achieve safer treatment.

This study holds significance in that it is the first study to survey common side effects encountered by clinicians [11] when using botulinum toxin in clinical practice. Emphasizing the importance of our study, the results of the questionnaire are reflected in the announcement of the 31st scientific conference of the KALDAT, which will cover "the most common side effects of botulinum toxin treatment and how to prevent them."

Unfortunately, due to concerns for security and anonymity of personal information, we were unable to analyze age and gender. Nonetheless, we were able to devise and implement an effective means for obtaining feedback from participants and organizers of academic conferences.

\section{CONCLUSION}

Firm understanding of the anatomy of the upper part of the face is important for safe and effective treatment with botulinum toxin. Development of a means with which to overcome the limitations of blind procedures would be beneficial to eliminating the occurrence of side effects associated with botulinum toxin treatment: application of ultrasound may be a good option.

\section{ACKNOWLEDGEMENTS}

We would like to thank the members of KALDAT who helped us conduct this survey. We would also like to thank Beon Jin Shin, CEO and Dong Hyun Kim, Programmer at MADE IN REAL Company who developed the real-time, web-based mobile survey system.

\section{CONFLICT OF INTEREST}

No potential conflict of interest relevant to this article was reported.

\section{REFERENCES}

1. Zarringam D, Decates T, Slijper HP, Velthuis P. Increased usage of botulinum toxin and hyaluronic acid fillers in young adults. J Eur Acad Dermatol Venereol. Forthcoming 2019. https://doi.org/10.1111/jdv.16481

2. Field $M$, Splevins $A$, Picaut $P$, van der Schans $M$, Langenberg J, Noort D, et al. AbobotulinumtoxinA (Dysport ${ }^{\circledR}$ ), OnabotulinumtoxinA (Botox ${ }^{\circledR}$ ), and IncobotulinumtoxinA (Xeomin ${ }^{\circledR}$ ) neurotoxin content and potential implications for duration of response in patients. Toxins (Basel) 2018;10:535.

3. Jankovic J, Brin MF. Therapeutic uses of botulinum toxin. N Engl J Med 1991;324:1186-94.

4. Yang HM, Kim HJ. Anatomical study of the corrugator supercilii muscle and its clinical implication with botulinum toxin A injection. Surg Radiol Anat 2013;35:817-21.

5. Johnson TP, Wislar JS. Response rates and nonresponse errors in surveys. JAMA 2012;307:1805-6.

6. Lorenc ZP, Smith S, Nestor M, Nelson D, Moradi A. Understanding the functional anatomy of the frontalis and glabel- 
lar complex for optimal aesthetic botulinum toxin type $A$ therapy. Aesthetic Plast Surg 2013;37:975-83.

7. Kwon KH, Shin KS, Yeon SH, Kwon DG. Application of botulinum toxin in maxillofacial field: Part II. Wrinkle, intraoral ulcer, and cranio-maxillofacial pain. Maxillofac Plast Reconstr Surg 2019;41:42.

8. Sundaram $\mathrm{H}$, Huang $\mathrm{PH}, \mathrm{Hsu} \mathrm{NJ}$, Huh $\mathrm{CH}, \mathrm{Wu} W T, \mathrm{Wu}$, et al. Aesthetic applications of botulinum toxin $\mathrm{A}$ in Asians: an international, multidisciplinary, pan-Asian consensus. Plast Reconstr Surg Glob Open 2016;4:e872.

9. Lee KC, Pascal AB, Halepas S, Koch A. What are the most commonly reported complications with cosmetic botulinum toxin type A treatments? J Oral Maxillofac Surg 2020;78:1190.e1-1190.e9.

10. Kim HJ, Seo KK, Lee HK, Kim J. Clinical anatomy of the face for filler and botulinum toxin injection. Singapore: Springer; 2016. p.55-92.

11. Cho Y, Lee HJ, Lee KW, Lee KL, Kang JS, Kim HJ. Ultrasonographic and three-dimensional analyses at the glabella and radix of the nose for botulinum neurotoxin injection procedures into the procerus muscle. Toxins (Basel) 2019;11:560. 